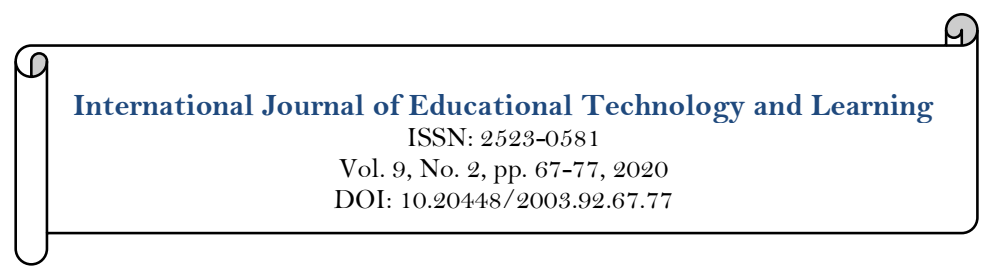

\title{
Consolidating Digital Partnerships between Academic Libraries in the Middle East and North Africa: A Prospective Study
}

\author{
Mohamed A. Abdulla
}

Faculty Member, Deanship of Graduate Studies $\Xi$ Research Prince Mohammad Bin Fahd University, Saudi Arabia. Email:mabdulla@pmu.edu.sa

\section{Abstract}

The study aims to discuss the issues of strengthening digital relations between the academic libraries in the MENA and the related issues to the Open access sources, shared databases, sharing intellectual property, and activation of collaboration agendas between MENA academic libraries, by international standards. Also, to review the available partnerships among academic libraries in the Middle East and North Africa, which was the result of the libraries transformation to the digital age. The new role for academic libraries required how joining digital information resources can allow each of the contributing partners to reach new local and worldwide users (Courtney, 2009). There are several forms of academic libraries such as interactive lending, cooperative supply projects, central indexing, union catalogue, reference services, cooperative storage projects, regional cooperation in the field of computers and equipment and exchange of experiences. The current study efforts to highlight review and analyze these partnership issues.
Keywords: Digital partnership

Academic libraries

Information sharing

Open access sources

MENA.

Licensed:

This work is licensed under a

Creative Commons Attribution 4.0

License.

Publisher:

Scientific Publishing Institute

Received: 15 October 2020

Revised: 10 November 2020

Accepted: 25 October 2020

Published: 8 December 2020

Funding: This study received no specific financial support.

Competing Interests: The author declares that there are no conflicts of interests regarding the publication of this paper.

\section{Introduction}

Coordination between libraries has been known since ancient times and to date, and coordination and cooperation between academic libraries have become one of the basics of library work as cooperation between libraries helps to facilitate numerous procedures and processes such as the provision of new scientific books and the sharing of new information sources, and the need for collaboration between academic libraries is bigger than ever, university budgets, also to many other publicly funded institutions, have been constriction significantly since the 2008 financial crisis, and academic libraries must find out how to stretch their budgets farther than ever, at least within the recent past. Meg (2016) other challenging academic libraries face is the revolution of the digital age in academia to demonstrate value to the academic community and beyond. The evaluation of the Library today is based on its activity in providing distinctive digital services to beneficiaries, and the provision of remote library services has become an increasingly necessary activity for academic libraries so digital partnership in light of the rapid breeding of intellectual production and the resulting inflation of intellectual production and the explosion of information or knowledge, etc. which led to a huge increase in different sciences and knowledge is very important.

Therefore, the digital environment is one of its components and content digital technology, and the users communicate from anywhere and from any device to access the information needs, from this view digital environment it is the internet environment. The academic libraries image has changed with the change of their services and information resources, modern technology has greatly influenced the academic libraries services, and many new concepts have emerged such as electronic publishing and digital libraries, which store a huge of 
information that can be easily shared. Cooperation and digital partnership between academic libraries have become an imperative in the digital environment, which has highlighted new features that take many forms, and there is no doubt about the need for information sharing and cooperation between academic libraries because it is impossible to understand each library for the huge of intellectual scientific production. So what is the concept of electronic cooperation between academic institutions, digital partnership in general means working together to reach the same goal of providing information to the users, so the digital partnership between academic libraries in a simple definition means, facilitating the interlibrary loan, sharing digital resources, central indexing, union catalog, reference services, between two libraries or more, following the rules and agreed upon by cooperating libraries? The digital partnership between academic libraries takes many forms, as is done at several stages of the life of cooperating libraries, and the concept of cooperation between libraries has changed, with all the library activities, processes, services, and facilities that one or more libraries can provide, and through these collaborative activities, they are involved in providing as much as possible the information resources and library services to the users.

However, cooperation between academic libraries is a shared responsibility and jointed work among numerous institutions, to use the available information sources on the best used by the library users, as well as to increase the accessibility to intellectual scientific productivity in all its forms at the lowest costs, so the importance for cooperation between academic libraries among themselves at the local, regional and international levels. The current study discussed and analyzed the opportunities and challenges for consolidating digital partnerships between academic libraries in the Middle East and North Africa, and the promotion of sharing digital sources, librarian experiences, activate the agendas, and collaborative projects. Then a proposed future development plan to consolidate the digital partnership between academic libraries in the Middle East and North Africa, and put forward some ideas and recommendations to achieve this goal.

\section{Problem Statement}

Academic libraries in the Middle East and North Africa already had digital collections available on the internet, but most of them don't share their digital collections with other libraries. Despite of the availability of networks, servers, professional librarians, and computers, but the local budgets for academic libraries have constricted, and funding opportunities have dried up as well (Guarria \& Wang, 2011; Lorenzen, 2010; Trail, 2013). Also, the understanding for benefit of the digital partnership still required more analysis and study, which requires the promotion of cooperation and sharing of digital collections, experiences and digital services, information sharing. the availability of cooperation between academic libraries in the Middle East and North Africa faces numerous challenges due to the conflict in this area, in light of these ideological differences and conflicts between the countries, academic libraries find difficulty to achieve integrated cooperation, is based on the main question: how to promote and activate the current digital partnerships between academic libraries in the Middle East and North Africa? What are the benefits of sharing digital information for academic purposes, specifically; the study answers the following questions:

1. What are the current partnerships between academic libraries in the Middle East and North Africa, and how can it be developed with future challenges?

2. How to consolidate the digital partnership between academic libraries in the Middle East and North Africa in the digital environment?

3. What are the ideal methods to activate the agendas of collaboration between academic libraries in the MENA in the field of digital transformation and exchange of experiences?

4. How to strengthen collaborative partnerships between librarians and information specialists in academic libraries in the MENA?

5. What are the challenges and opportunities for collaborative projects between academic libraries in the Middle East and North Africa?

6. How to contribute to the developing plans between academic libraries in the Middle East and North Africa for sharing facilities, operations, policies, and agreements?

\section{Objectives}

The study seeks to achieve the following objectives:

1. To analyzing and evaluate the current partnerships between MENA academic libraries, with the challenges in the digital environment in the future.

2. To consolidate the digital partnership between academic libraries in the Middle East and North Africa by combining digital storage, digital services, digital information sharing, and digital activities.

3. To activate the collaboration frameworks between academic libraries in the Middle East and North Africa in the field of digital transformation, and sharing experiences.

4. To promote collaborative partnerships between librarians and information specialists in the MENA academic libraries.

5. To identify the opportunities and challenges for digital partnership between academic libraries in the Middle East and North Africa. 


\section{The Methodology}

To meet the requirements of this study, the researcher used two methodologies, questionnaire sources method for the study of the literature review, this method has been applied to review the literature, resources, and references on the subject of this study and to give the historical background to the study problem. And analysis techniques method aims at a quantitative and qualitative description of the problem and seeks to analyze the relationship between future objectives and digital partnerships in the MENA, to find mechanisms to strengthen cooperation and coordination projects between MENA academic libraries, especially about bibliographic information bases and digital content for private groups, to enhance their utilization and investment in the best way.

\section{Literature Review}

Digitization of the humanities began in the mid-1990s after the advent of the internet: humanities scientists became aware of the network's potential by creating digital archives. One of the best-known examples of this period is the Perseus Digital Library, a digital resource of Greek and Latin texts conceived by Tufts University. All documents relating to Greek documents from the 5th and 4th centuries BC are included. Less wide in content, but still important, it is the Latin Library. Most documents are enriched by English translations, critical comments, and educational materials. Academic libraries, information professionals, and librarians have expected a crucial role by taking part in digital humanities projects (Maria, 2017). Academic Libraries can provide competitive services under budgetary constraints. A New York Library Consortium's experience, and the Southeast New York Library Resource Council is considering the merging of its service and sharing for more cost-saving options and integrate its services with other regional libraries to develop and meet changing public demands more effectively (US Gov 1, 2020).

For more examples of digital partnerships and collaborations between the academic library, the Association of Research Libraries (ARL) has published an ARL SPEC 326 kit devoted to the topic of digital humanities (Tim, Miriam, Alain, \& Stewart, 2011). Therefore, these digital partnerships should be seen as a radical departure from the traditional strengths of research libraries. In fact, these strengths reflect and complement needs at the heart of the digital humanities (Vandegrift \& Varner, 2013). Maria noted that the correlation between academic libraries and digital humanities extends side by three closely related levels:

- $\quad$ Spatial level, i.e. physical sharing of space, expertise librarians, and equipment.

- The service-oriented level, i.e. services and tools developed by academic librarians and information professionals to support research in the digital humanities.

- Professional level, i.e. skills and experience acquired by academic librarians in the Digital Partnership of Humanities Projects.

The Middle East and North Africa experiences mentioned in this study, make us rethink that academic libraries in their traditional form do not meet the requirements of the digital age as we mentioned before, therefore academic libraries must understand the radical change that has taken place in the production, distribution and use of the information resources by modern technologies and new information formats. So academic libraries can begin to formulate a new different visions (Bernard, 2003) and it is well to understand the main dynamics and challenges facing academic institutions and academic libraries today, these challenges are dealt with scientifically and logically. In 2017, a grant planning proposal has been submitted for exploratory research, community building, and technical models of the Digital Library in the Middle East. The following experiences are a real example in the MENA partnerships for academic libraries, which the researcher discussed and analyzed the general consequences of consolidating digital partnerships between academic libraries:

\subsection{The World Digital Library}

(WDL) is a project of the U.S. Library of Congress, it's a largest digital partnership that enhances collaboration and sharing of information resources, and expertise librarians between libraries, and the WDL consists of partners such as libraries, archive, or other institutions that have digital collections of cultural content contribute to the creation of WDL collections. Partners may also be private institutions and foundations that contribute to the WDL project in other ways, for example through sharing technology, working group meetings, co-sponsorship, or financial contribution, However, most libraries participating in the World Digital Library are not university libraries (WDL,2020).

\subsection{Experience of DLME}

The Middle East Digital Library project was proposed by an engineering team from CLIR and Stanford Libraries. The aim of this project to gathering the information resources of the Middle East from around the world, the Library platform offers free and open access to the rich cultural legacy of the MENA by transporting together collections from a wide range of cultural heritage institutions in the world. This is due of the continuing terrorizations to the cultural heritage in the Middle East and North Africa through damage, prowling, and illegal trade, making these information resources accessible data about collections from around the world. The first version of the DLME available to the public in the open-source platform. DLME 
combines high-resolution digital images of cultural objects from the Middle East, including objects collected by cultural organizations in MENA, as well as digital items related to the Cultural Heritage of the Middle East in All over the world. Also, digitization and cataloguing of museums and physical archival objects as well as available objects from the websites have all been supported throughout the Middle East to enrich the range of cultural material published online. The project contains 127,444 documents in five types available in 51 languages including the Arabic language and has shared content through 20 contributors around the world as shown in the Table 1.

Table-1. The collections of The Middle East Digital Library project

\begin{tabular}{l|c|c|c}
\multicolumn{4}{c}{ Table-1. The collections of The Middle East Digital Library project } \\
\hline Institution & Countries & Collections & Items \\
\hline American Numismatic Society & US & 1 & 7,748 \\
\hline American University in Cairo & Egypt & 23 & 5,553 \\
\hline American University of Beirut & Lebanon & 3 & 16,646 \\
\hline Ancient Near Eastern Art, Metropolitan Museum of Art, New York & US & 1 & 6,175 \\
\hline British Library. India Office Records and Private Papers & UK & 18 & 17,244 \\
\hline CLUSTER & Egypt & 1 & 2 \\
\hline Cambridge University Library & UK & 3 & 22,308 \\
\hline Consejo Superior de Investigaciones Científicas (CSIC) & Spain & 1 & 160 \\
\hline David Rumsey Map Center, Stanford Libraries & US & 1 & 103 \\
\hline Fine Arts Library, Harvard University & US & 1 & 11,707 \\
\hline Institut dominicain d'etudes orientales & Egypt & 1 & 60 \\
\hline Institut français d'archéologie orientale & Egypt & 1 & 278 \\
\hline Palestine Poster Project Archive & US & 1 & 12,920 \\
\hline Penn Museum & US & 2 & 15,959 \\
\hline Princeton University Library & US & 4 & 3,408 \\
\hline Sakip Sabanci Museum & Turkey & 4 & 3,438 \\
\hline Shahre Farang & US & 3 & 414 \\
\hline Texas Tech University Libraries & US & 1 & 2,210 \\
\hline The American Institute for Maghrib Studies & Algeria, & 1 & 71 \\
\hline University of Michigan & Torocco, & &
\end{tabular}

\subsection{SDL Experience}

The Saudi Digital Library (SDL) is the largest collection of digital information resources in the Arab world, with more than 680,000 digital books in full text, 174 international and Arabic information bases covering the full texts of millions of academic articles, more than 7 million university theses and dissertations and 7 million multimedia, including images and scientific films in various scientific disciplines, which are within the reach of the attention of educational institutions and obtained through more than 300 international publishers. The SDL is one of cooperation and joint integration between the academic libraries, where it's a list of 40 academic partners and the scientific and cultural sector scoring all Saudi universities and colleges, in addition to numerous scientific and research centers. And the integration in Saudi Digital Library Corporation is an added value to the field of scientific research and knowledge in terms of exceeding the effects and limitations of time and space facing the traditional libraries and its users, SDL provides E-resources to all Saudi universities in one umbrella, through which to negotiate with International publishers on numerous legal issues and financial, in this significant Saudi academic libraries savings of money and efforts, through the union urges one umbrella, which academic libraries can get more benefits and rights to publishers, also an opportunity to strengthen the relationship of Saudi academic libraries, and enhance the status of Saudi universities on the academic accreditation by repetition its digital resources (SDL, 2020).

There are many benefits of the joint scientific cooperation offered by the Saudi Digital Library as follows:

- Promoting opportunities for Saudi Research Achievements through publishing research output.

- Enhancing researcher output at Saudi Universities, promote the researchers at Saudi universities participation in the global academic community and raise the status of Saudi universities.

- Introducing numerous new initiatives that support the academic and research community in Saudi universities.

- Increasing access to theses and dissertations from Saudi universities, and make it available to the international academic community. 


\subsection{MAEEN Experience}

In Saudi Arabia, the pilot version of the Research and Academic Network (NREN) was established, in order to meet the needs for advanced scientific research and to achieve cooperation and communication between research centers, universities, and other academic institutions to accomplish the required research efficiently. NREN is a certain network infrastructure established by King Abdul-Aziz City for Science and Technology, characterized by its ability to meet the requirements of scientific research from speed and efficiency in the transfer of data between its subscribers and to provide access to unique applications and services. In addition, this network provides interconnection with similar research networks in Europe, America, and Asia, to facilitate communication between researchers around the world. And to meets the requirements of the research and educational community in the areas of data transfer, networking, applications, and electronic services more information in the below figure:

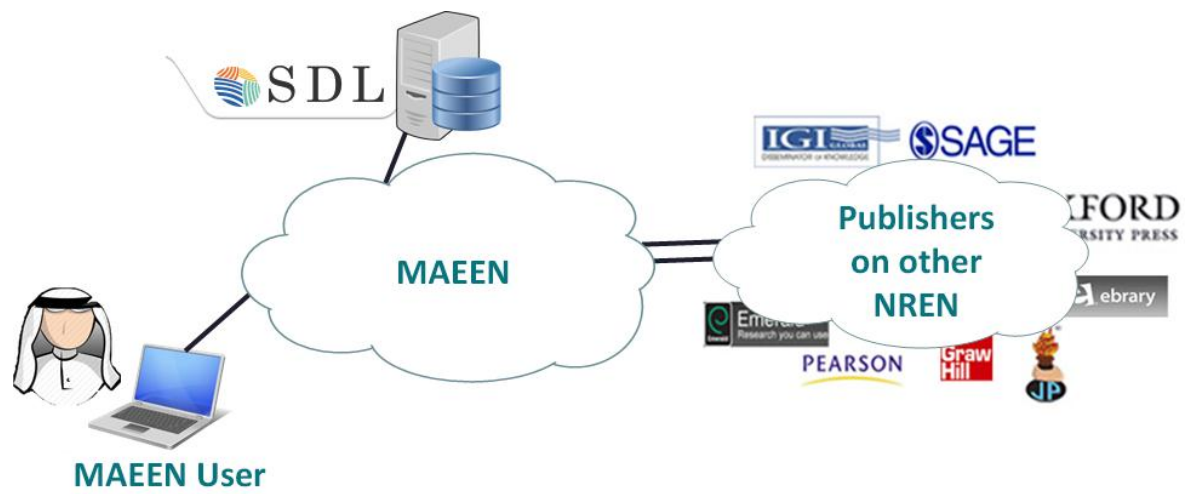

Figure-1. MAEEN website, 2020.

From the Figure 1, it is clear that the MAEEN network provides several services, including the integration of electronic libraries and easy access to Catalog services (MAEEN, 2020).

\subsection{AUC Experience}

The Arabic Union Catalogue was established in 2007 by the King Abdul-Aziz Public Library, it's an integrated collaborative project to provide knowledge services through a joint collaborative platform that brings together knowledge and culture institutions in the Arab world, within the framework of collaborative work among libraries in the Arab world. AUC was applied and operated by Naseej Company which specialized in libraries and information centers, which contributed to the automation of hundreds of big libraries. The community of Arabic Union catalogue has been established with nearly $(5,000)$ libraries from (500) institutions from (27) countries, in 2017 The Arabic Union Catalogue became a knowledge platform, and provides a variety of knowledge services which designed to enable the members to serve their communities with better information services, thus contributing for improving the cultural and cognitive impact of AUC library members, by providing new, high-quality services (ARUC, 2020).

AUC an excellent model of cooperation between librarians and information specialists in the sharing of bibliographic records and online cataloguing for subscribing libraries, and cooperation in sharing online library catalogue (OPAC), as well as the provision of advanced training service for librarians and information professionals, which is to provide advanced training courses in all aspects of the process of bibliographic and authority files.

\subsection{The Experience of LIWA}

LIWA project was established as a collaborative project for the United Arab Emirates higher education institutions, LIWA aims to provides a single interface for research in UAE libraries online Catalog, and the idea of this project is to provide a combined Catalog for all libraries at the College of Higher Technology with Sheikh Zayed University, LIWA union Catalog provide searchable for more than One million books and other information sources held by contributing libraries in the UAE. Through LIWA, university faculty members, researchers and students in joining academic institutions can request books within their areas of interest and are not available in their libraries. The LIWA can be accessed from anywhere in the same way that users are seeing for a home library Catalog (LIWA Website, 2020) the below figure shows the services in LIWA from the user interface: 


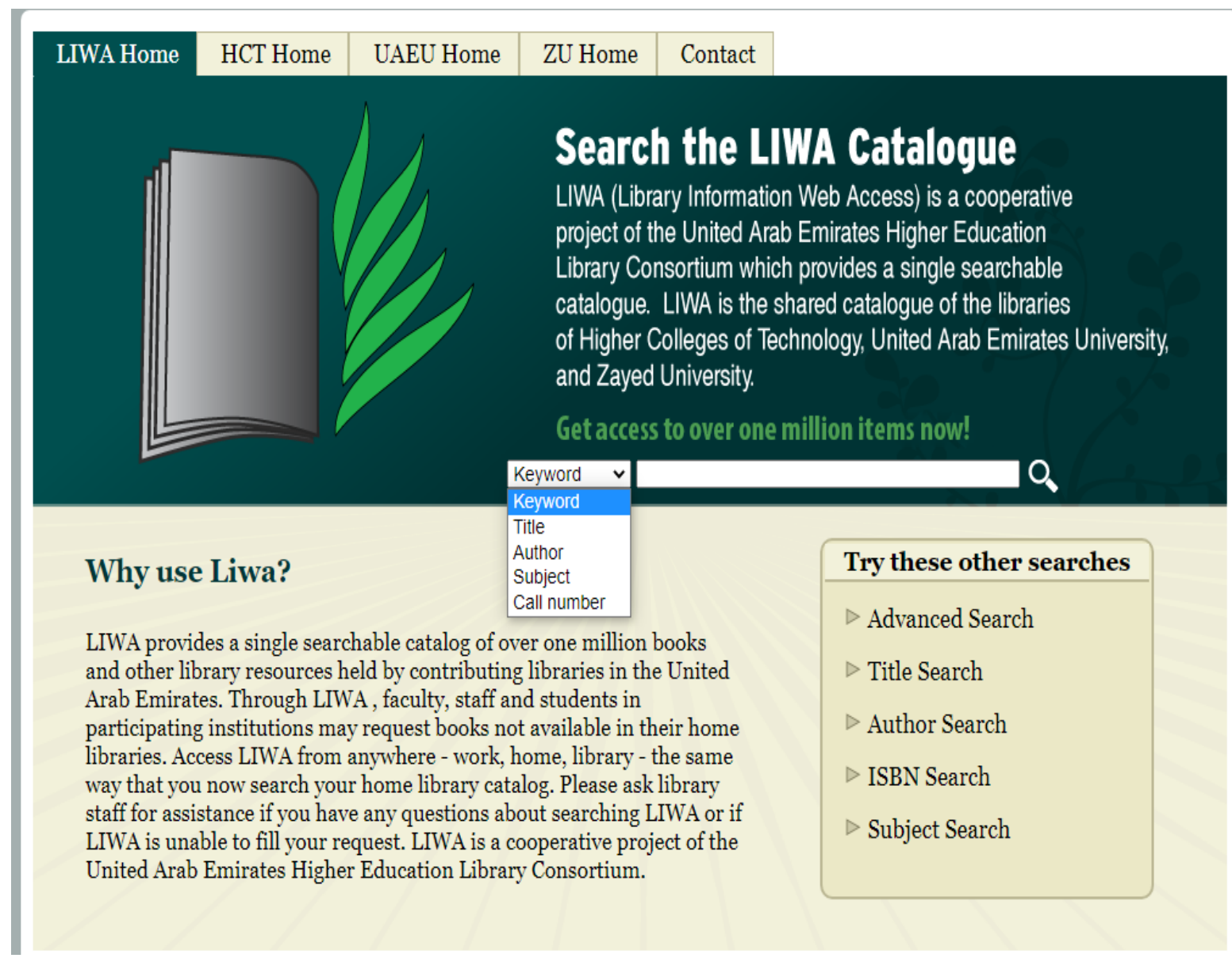

Figure-2. LIWA website, 2020.

From the Figure 2, shows that LIWA is a collaborative project of the UAE Higher Education Libraries Association, from the LIWA Portal users, can search for more than one million books from contributing library collections to this project in the UAE. Through LIWA, faculty, staff, and students can requesting books that are not available in their home libraries. Users can access LIWA from anywhere, in the same way; users are looking at the home library Catalog

\subsection{AFLI Experience}

The Arab Federation of Libraries and Information (AFLI) was established to strengthen the relations of cooperation between library associations in the Arab world, as well as seeking to improve the level of education in institutions preparing and qualifying librarians and information specialists. AFLI has done a lot of work as a regional professional association to develop the performance of the librarians and information professionals in academic libraries, Public libraries, School Libraries information centers, and archives through many activities such as workshops, training courses, annual conferences and seminars, and has even extended to the establishment of Arab standards in libraries files and translation of International standards, especially the IFLA standards, to be available to the Arab libraries community in its language, so that it reaches the largest number of librarians in the library and information field. The International Network of Emerging Creative Librarians Network - Middle East and North Africa (MENA) is one of the top five projects in the 9th E-Learning Branch of the United Nations Information Society Summit, and this project is a model of cooperation in the field of training for librarians (AFLI website, 2014). Since 1988, the AFLI has organized several scientific activities from seminars and conferences that have brought together a considerable number of librarians and information specialists in the field of library sciences to get to know each other, cooperate and coordinate their efforts to raise the profile of the library profession and to introduce it within the Arab world, and internationally. Some examples of these activities are the 17th Conference on under the title: Let's Make Information Available to All: A Partnership between Librarians and Archivists," Algeria, March 2006. Also the 18th Conference on the Libraries Profession under the title, The Role of libraries and the Challenges of Reality and the Future in Free Access to Scientific Information, Jeddah (Saudi Arabia) in November 2007. One of the best scientific activities for partnerships held by the AFLI is the 19th Conference on Cooperation between Arab Information Institutions and Facilities in the Age of Digitization, Cairo (Arab Republic of Egypt) in November 2008, in this conference the experiences were shared between librarians in the Arab world and MELA region. 


\subsection{The Experience of Lebanese Academic Libraries}

In January 2002, the libraries of four private academic institutions established the Lebanese Academic Library Consortium (LALC), are (library of American University of Beirut, the library of Lebanese American University, library of Notre-Dame University and the library of University of Balamand), the first library consortium in Lebanon. Starting with four members in 2002, two libraries were joined in 2008 (The library of university Saint-Esprit de Kaslik and the library of University Saint-Joseph) to become a member of six academic libraries, finally the LALC has eight members in 2011 after joining both the library of Beirut Arab University and the library of Haigazian University to participate in one or more databases. The LALC mission is to "collaborate on the selection, pricing and access to electronic sources", for the joint cooperation of 9 universities libraries and their users participating in one or more databases., for example, the Elsevier Science Direct database accessible to all LALC members, which was signed by LALC in 2002. LALC is part of a bigger libraries group called the International Coalition of Library Consortia (LALC, 2020).

\subsection{The Experience of the Egyptian Universities Libraries}

Including 40 academic institutions in Egypt, is one platform provides Egyptian University Library Collections, such as Master's and Thesis for Egyptian Researchers, Dissertations and Thesis understudy at Egyptian universities, Research productivity for the faculty members at Egyptian universities, Scientific journals published by Egyptian universities, Electronic acquisitions owned by Egyptian universities, and Archival recording of electronic lectures. As well as connect with major international libraries to learn about the latest publications, and Communicating with the world's largest databases shared by the Supreme Council of Universities to learn about the latest worldwide scientific research in addition to accessing more than 25 thousand periodicals with full text (EULC,2020). The Federation of Egyptian academic libraries has organized numerous training courses on the use of international databases and on how to search in the OPAC, the Federation has begun to build a union Catalog of the collections of Egyptian government university libraries in May 2007, this contains the Catalog of more than 1500 bibliographical records form more than 300 Egyptian universities, and this experiment sample of cooperation between the academic libraries, as can also be referred to the experience of the Egyptian National Network for Scientific and Technological Information, which has built a unified list of periodicals available in Egyptian university libraries, which includes More than 21000 titles form more than 370 academic libraries.

\subsection{The Experience of Jordan universities Libraries}

The Libraries cooperation in Jordan was established to manage the official universities libraries network as the "Center of Excellence for Jordanian Public University Library Services", this center located at Yarmouk University (Irbid, Jordan), the establish of this center based on a memo of understanding signed by all Jordanian public universities, and according to the letter of the Minister of Higher Education, he agreed that Yarmouk University will be the headquarters of this Excellence center on April 27, 2004. Jordan Libraries cooperation consists of ten university libraries and their users, the status of the center signed in 11 articles of instructions for the provided services by Jordanian university libraries (COE Website, 2020). A "Maktabati Consortium Mission managing the information network of the Jordanian University Libraries and coordinating their several services to achieve explanation of expenditures, classifying contribution of information resources, and standardizing mechanisms and work tools between the member libraries.

\subsection{The Experience of Tunisia Universities Libraries}

The University Libraries network in Tunisia Network, known as Al-Biruni Network, is a group of libraries in the higher education and scientific research institutions, and under the supervision of the Ministry of Higher Education for scientific research or joint supervision with other ministries.

This network aims to create a union catalog of the Tunisian university libraries, as well as to standardize the working methods and documentation policy for the Tunisian higher education and scientific research sectors by adopting the international standard in the libraries and information fields. Al-Biruni network has about 400 accounts for librarians, 180 online library catalogs including 900.000 titles, serving faculty members, researchers, and students in 13 universities, 5 research centers, and the General Directorate of Technological Studies in Tunisia. (BIRUNI, 2019), the following chart shows Access statistics for the new website of the University Library Network for 2019. 


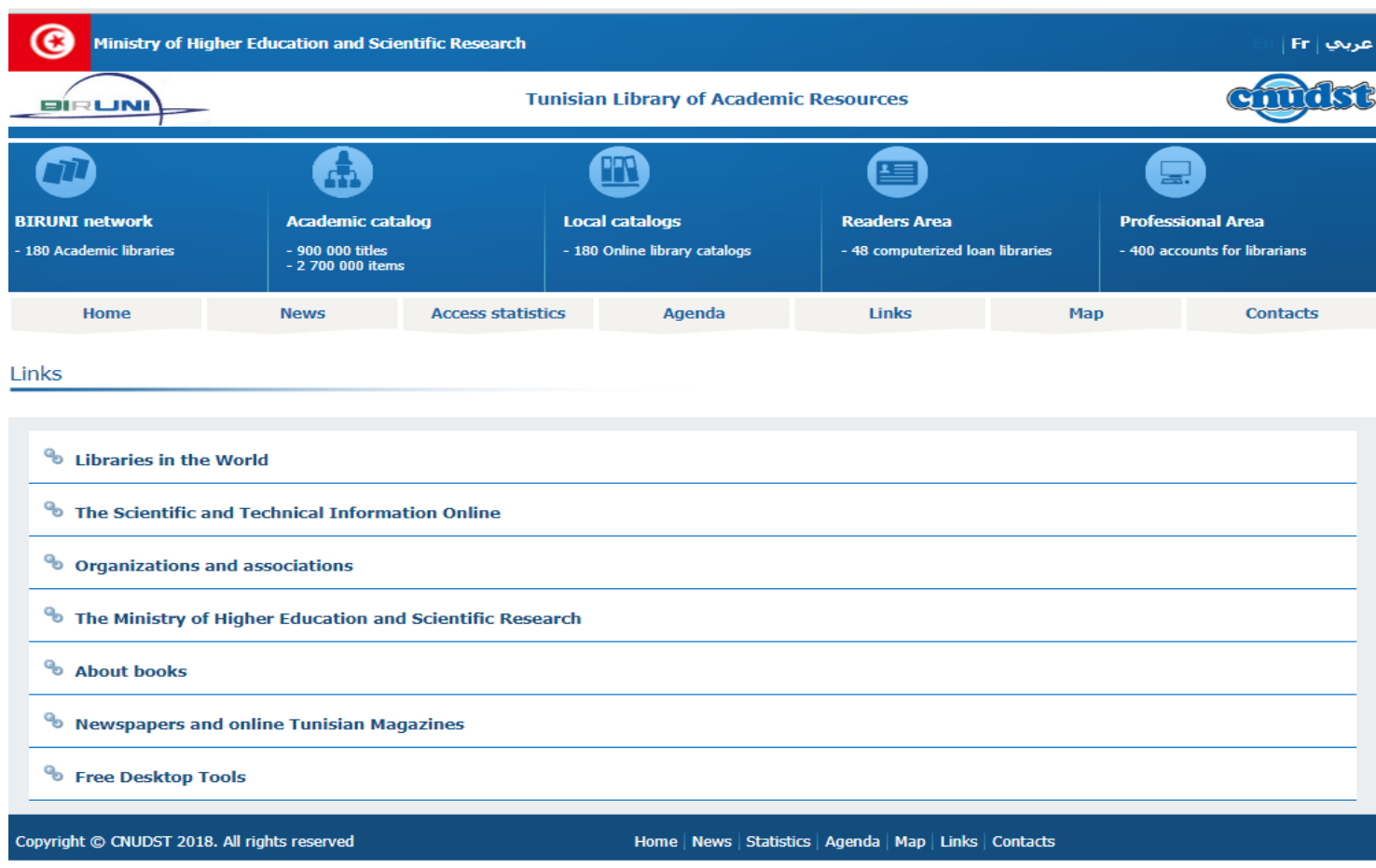

Figure-3. Tunisian Library of Academic Resources - CNUDST

Figure 3 shows the collections of 180 Tunisia academic libraries, the number of available titles and items on the OPAC, and users access statistical data.

\subsection{The Experience of Palestinian Universities Libraries}

The Palestinian Library Association was established at the initiative of a group of interested librarians, who held its first meeting on April 29, 1985, to create a nucleus for an association or committee of academic libraries and research centers, and a preparatory committee was formed to coordinate and prepare for the topic. The first projects of the Committee appeared in 1986 by working to unify the heads of Arab topics and adopt ingesting the list of formal divisions.

In 1994, the project of periodical catalog union (PLILL) was established with the support of the AMIDEAST. In 1998, a draft proposal was launched to establish the Union catalog of Palestinian Universities with the support of UNESCO, under the supervision and coordination of Birzeit University and Jerusalem University College. In 2005, all Palestinian universities were collectively subscribed to the EBSCO database, in 2008 subscribed to the Science Direct database. Palestinian university libraries including 11 universities joined the EIFL Union of Electronic Sources, and Palestinian universities were excused from paying membership fees for two following years in 2005 and 2006 (PALICO, 2020).

\subsection{The Experience of Sudanese Universities Libraries}

The Virtual Library of the Sudanese Research and Education Network was established in 2006, the first phase of the SUVL system was implemented in 2006, relying on free and open-source software. The team relied on MySQL and PHP software. The contents of three universities were developed (the University of Khartoum, Sudan University of Science and Technology, and International African University) and the number of records was 200,000 from the library catalog, research, and periodicals. SUVL aims to Support the national content productivity from knowledge, develop a union catalog of Sudanese scientific research to support the development in Sudan, and to provide a unified interface for academic libraries that enables higher education employees to retrieve information in an orderly and fast way. In 2007, the project management implemented the second phase of the introduction to include the content of 8 Sudanese universities: (University of Khartoum- Sudan University of Science and Technology - Omdurman Islamic University Quran University - World African University - Neelian University - Al-Jazeera University - Al-Zaeem AlAlazhari University) to bring the total number of records to 350,000 records. In 2007 and 2008, the project management provided several training courses for the qualification of librarians at 27 government universities, and they trained in library quality standards and Marc 21 standards. In 2010, the Executive Management of the Sudanese University Information Network rebuilt the virtual library and designed the applications of the integrated digital library system with PMB software. It has also developed the Sudanese Unified Scientific Research Index. The network management has signed open access agreements with the IFL International Organization (SUVL, 2020). It should be noted here that The Sudanese Academic Library Consortium (SALC) was established in 2014, and EIFL provides access to scholarly E-Resources for Sudanese faculty members and 
researchers. In 2007 EIFL held an open access awareness raising and advocacy workshops, it's supported in the promotion of open access repositories at Sudanese universities, also the institutional repositories in Sudan project management committee composed of librarians, information professionals from the three universities, and chaired by the CEO of SudREN in 2012 and more than 180 librarians and IT staff has been trained (Iman, 2018).

\section{The Partnership for Academic Libraries in the MENA}

The concept of cooperation between academic libraries has been developed, so that all activities, processes, services, and facilities that a library can provide to one or more other libraries are called library partnership, through these collaborative activities, and involved in delivering library resources and services as possible between libraries. Given the future of cooperation between academic libraries in the Middle East and North Africa, we note that there are numerous benefits, including saving time, budget, and effort, particularly in metadata processing for information sources such as indexing, classification, and cataloguing, for Preventing and avoiding the repetition of the same work, joining standards, specifications and methods of work, as well as sharing experiences for trained professional librarians, exclusively for libraries that do not have library experts (Robert, 2015).

The availability for the Actual Corporation in the future for the academic libraries in the Middle East and North Africa requires taking benefits from the current experiences, consolidating, and supporting these partnerships. Also the needs for work within the available professional librarians and information specialist with providing the requirements equipment of digital partnership, which are:

\subsection{Partnership Prospects for Cooperative Acquisition}

In the 1980 s sharing of resources and cooperative acquisition programs for libraries cannot achieve maximum effectiveness unless librarians identify themselves, it is necessary to create relationships between librarians to enhance the cooperative supply and this is done through more conferences and events (Brzzard, 1986) today as a result of changes in digital publishing and in response to the users needs who have increased their demand for digital content, and in light of the new global trends of libraries. The digital collections development can be carried out cooperatively between academic libraries in MENA, through cooperative procurement, particularly in the expensive academic databases, it can be agreed to obtain a certain set of academic databases, and make certain arrangements for subscription, to each library within MENA has the right to benefit in one form or another from, these digital sources and interlibrary loan between academic libraries is the dominant form in use of these resources, or through the central purchase of digital resources by one subscription (SDL Experience), and the main center of the MENA cooperative purchases the digital resources and share them to the MENA academic libraries.

\subsection{Partnership Prospects for Cooperative Storage}

Libraries in the MENA need to deal with the increasing numbers that are growing very rapidly in the digital resources, the $\mathrm{E}$-sources on the Internet or electronic devices need to provide storage for preservation, so it can be accessed continuously by the library users, numerous researchers have confirmed that the academic libraries must to provide a digital repository system as well as to have an ongoing research and development program (Lap, 1977; Saini, 2018; Xie \& Matusiak, 2016) academic libraries in MENA region required to develop strategies for digital preservation and migration of the digital resources, the initiative of National Library of Australia in Preserving Access to Digital Information (PADI) can be helped, by providing mechanisms that will help to ensure the available digital resources in MENA academic libraries effectively managed, with a focus on maintaining and accessing in the future.

\subsection{Partnership Prospects for Union Catalog}

The Arab Union Catalog is one of the important infrastructure programs for cooperation between academic libraries in the Middle East and North Africa, it covers most countries in the MENA region, and works to attract the bibliographic information resources, that represent the published and unpublished Arab intellectual output, founded in the Arab and foreign libraries, AUC is a big bibliographic database based on international standards, that standardize the data and the information resources, and facilitate to sharing of bibliographic recordings between online libraries, to avoid the repetition of cataloguing of the information resources in tens or even hundreds of times within Arab libraries (ARUC,2020).

\subsection{Partnership Prospects for Interlibrary Loan}

Interlibrary loan is the main services in academic libraries, it's one of the important indicators for the effectiveness of the library and its relationship with the users community, and also is a good criterion for measuring the effectiveness of libraries in providing their services and achieving their objectives. Academic libraries in the MENA can activate this service by activating the service within the country, and then making partnerships between the Middle East and North Africa countries. Through online interlibrary loan between 
participating libraries in the MENA, network terminals, for providing sufficient information about libraries that have the required resources for borrowing.

\subsection{Partnership Prospects for Academic Database Subscription}

This service can be provided jointly in the subscript of $\mathrm{E}$ - sources in academic databases and make them available to all users of academic libraries in the Middle East and North Africa, the same way that the Saudi Digital Library works, or through support for digital information storage systems.

\subsection{Partnership Prospects for Cooperative Reference Services}

The American Library Association ALA define cooperative Reference Services is a virtual reference service that is provided electronically, often in the same real-time. The researcher suggests for establishing cooperative reference serves in MENA academic libraries, to achieving the principle of sharing resources between academic libraries to reach the answer of users queries easily and quickly, that achieves the satisfaction of the students, faculty, and staff, to overcomes spatial and temporal barriers, and to success on this service among academic libraries in MENA, it is necessary to provide administrative and technical requirements that academic libraries should observe, to provide optimal services, such as planning to standardize the vision between academic libraries, provide funding, select programs with a free remote server, select open-source programs, appropriate hardware, design appropriate interfaces, expert staff, policy development, and legislation, and benefit from successful projects As Question Point (QP) or Ask snow project.

\section{Discussion}

The reality of academic libraries work in numerous countries of the Middle East and North Africa indicates that no library can provide all beneficiaries needs in the light of the knowledge explosion, which made digital cooperation between academic libraries a necessity in the future of these libraries, but the clusters between libraries facing many challenges. For example, the economic constraints, which the academic libraries MENA has a limited budget, also the human constraints, which are the lack of qualified library staff, and the absence of training and development programs, and the cultural constraints represented by unstable governments in the Middle East and North Africa. Centrality in decision-making, lack of government attention and support libraries, lack of regulation of libraries and information centers, and lack of information sources. All of these constraints make the vision of the success of a collaborative project in the future to guarantees all academic libraries in this area difficult to implement, but the success of some global corporations in helping some libraries to carry out their tasks makes them preferable practices that can be emulated and used by their programs in developing Academic libraries in the Middle East and North Africa.

It is necessary to find a strategic development mechanism for academic libraries and their future cultural and knowledge plans in the Middle East and North Africa, with an interest in collaborating with cultural and scientific institutions. In addition to the programs that the academic libraries are working on in terms of developing its various, cultural projects that deal with sources of knowledge. The academic libraries collections of documents, manuscripts, books, and rare photographs are invested in exhibitions that benefit the Middle East and North Africa reader and researcher, and the academic libraries pioneers are informed of the most prominent scenes and transformations in the Middle East and North Africa history. The researcher proposed several initiatives focusing on cooperation between academic libraries in the Middle East and North Africa, such as the initiative to review the role of academic libraries in form and content and make them attractive reading clubs, as well as the Initiative of the Middle East Interactive Reading Platform to encourage reading and interactive E-publishing.

\section{Conclusion}

The benefits for consolidating digital partnerships between academic libraries in the Middle East and North Africa will bring great benefits in light of the new digital trend, and the growing demand for information resources showed the urgent need for partnerships and cooperation between academic libraries to provide the needs of beneficiaries, given the access to information sources as possible and the expansion of the circle of contribution and sharing, which makes the services libraries better. The cooperation between academic libraries has become an important issue, especially the issue of networking and the information sharing between networks that are available in academic libraries, forever from encouraging libraries to create a big database and computerization the contents and operations and take advantage of the free opportunities provided by organizations working in the field of free open-access information.

Prospects to activate collaboration frameworks in the field of digital transformation, and sharing experiences. To strengthen collaborative partnerships between librarians and information specialists in academic libraries in the Middle East and North Africa, professional associations such as the MENA, AFLI, SLA/ AGC, AUC, or countries library associations in the region can be used. In addition, the official deposit system for information exchange of the world health organization (IRIS) can be used and advocated for use. 
To encourage other libraries to use and share these promotional materials on websites via social networks, email and during events.

\section{References}

Bernard, F. R. J. (2003). Message from CRL president bernard reilly, center for research libraries: Global resources network. 22(3).Available at: https://www.crl.edu/focus/article/590.

Brzzard, M. L. (1986). Cooperative acquisitions within a system, the university. Of California Shared Purchase Program (pp. 99-113). Luquire, Coordinating Cooperative Collection Development.

Courtney, N. (2009). Academic library outreach: Beyond the campus walls. London: Westport, Conn: Libraries Unlimited.

Guarria, C. I., \& Wang, Z. (2011). The economic crisis and its effect on libraries. New Library World, 112(6), 199214.Available at: 10.1108 .03074801111136248 .

Iman, A. (2018). Institutional repositories in Sudan. Paper presented at the COAR Annual Meeting, Hamburg, 14-17 May 2018.

Lap, C. D. (1977). Resource sharing and cooperative acquisitions: A guardedly optimistic view. Library Acquisitions: Practice \& Theory, I(3), 201-208.Available at: https://doi.org/10.1016/0364-6408(77)90032-1.

Lorenzen, M. (2010). Fund raising for academic libraries: What works, what doesn't? Library Philosophy and Practice, $e$ (ejournal), 1 .

Maria, C. (2017). New trends in academic library partnerships: Academic libraries and digital humanities. Paper presented at the Proceedings of the IATUL Conferences. Paper 2.

Meg, H. (2016). Successful partnerships for academic libraries. Journal of New Librarianship, 1, 28-54.

Robert, A. S. (2015). Resource sharing begins at home: Opportunities for library partnerships on a university campus. Resource, 10, 3-2015.

Saini, O. P. (2018). Understanding the role of institutional repository in digital preservation in academic libraries: A review of literature. Library Philosophy and Practice, 1-14.

Tim, B., Miriam, P., Alain, S. P., \& Stewart, V. (2011). SPEC Kit 326: Digital humanities" (Novemb 326: Digital Humanities (November 2011) Association of Research Libraries, 2011. Retrieved from http://publications.arl.org/Digital-Humanities-SPEC-Kit-326/ $\quad$ (http://publications.arl.org/DigitalHumanities-S.

Trail, M. A. (2013). Evolving with the faculty to face library budget cuts. The Serials Librarian, 65(2), 213-220.Available at: https://doi.org/10.1080/0361526x.2013.802268.

Vandegrift, M., \& Varner, S. (2013). Evolving in common: Creating mutually supportive relationships between libraries and the digital humanities. Journal of Library Administration, 53(1), 67-78.Available at: https://doi.org/10.1080/01930826.2013.756699.

Xie, I., \& Matusiak, K. (2016). Discover digital libraries: Theory and practice (pp. 388). Amsterdam: Elsevier.

Websites:

AFLI (2020, December) Arab Federation for Libraries and Information .Retrieved December 06, 2020, from: http://arabafli.org/main/post_details.php?alias=Afli6

ARUC Website (2020, December). Arab Union Catalogue, Riyadh , Retrieved December 06, 2020, from: https://www.aruc.org/en/definition

BIRUNI (2018, December). Tunisian Library of Academic Resources. Retrieved December 06, 2020, from: http://www.bu.turen.tn/v-en/links.php

EULC (2020, December). Egyptian Universities Libraries consortium. Mansoura University Retrieved December 06, 2020, from: http://www.eulc.edu.eg/eulc_v5/libraries/start.aspx? DefaultLang=En\&Applang=E\&ScopeID=1.\&

ICOLC, T. (2016, February 27). Center of Excellence for Jordanian Public University Library Services. Retrieved December 06, 2020, from https://icolc.net/consortia/365

L. C. (2020, December). World Digital Library. Retrieved December 06, 2020, from https://www.librarianshipstudies.com/2020/04/world-digital-library.html

LALC (2020, December) Lebanese Academic Library Consortium .Retrieved December 06, 2020, from: http://lalc.lau.edu.lb/

LIWA (2020, December) LIWA project of the United Arab Emirates Higher Education Library Consortium. Retrieved December 06, 2020, from: https://zu.libguides.com/liwa\#s-lg-box-24631332

MAEEN (2020, December) Maeen Networks, Retrieved December 06, 2020, from: https://www.maeen.sa/en/

Mansoura University. (2007, January 1). Egyptian Universities Libraries consortium. Retrieved December 06, 2020, from http://srv3.eulc.edu.eg/eulc_v5/libraries/start.aspx?ScopeID=1.\&

PALICO (2009,June). Palastine Union Periodical Cataloge Project, Retrieved December 06, 2020, from: http://www.palico.ps/background.htm

S.D.L website. (2015, January 1). Saudi Digital Library. Retrieved December 06, 2020, from https://portal.sdl.edu.sa/english/

SUVL, S. (2020, December). SUVL: Sudanese Research and Education Network. Retrieved December 06, 2020, from http://suvl.sudren.edu.sd/index.php?direction=rtl 